\title{
Radiological Evaluation of Lower Genitourinary Tract Cysts in Males*
}

\author{
Ashraf Talaat Youssef \\ Department of Radiodiagnosis, Faculty of Medicine, Fayoum University, Al Fayoum, Egypt \\ Email: ashraftalaat1@yahoo.com
}

Received September 7, 2013; revised October 5, 2013; accepted October 13, 2013

Copyright (c) 2013 Ashraf Talaat Youssef. This is an open access article distributed under the Creative Commons Attribution License, which permits unrestricted use, distribution, and reproduction in any medium, provided the original work is properly cited.

\begin{abstract}
Aim of the Work: The present wok aims to assess how to reach the optimum diagnosis of the nature and the complications of lower genitourinary tract cyst in male patient using different radiological imaging modalities. Patients and Methods: 1000 male patients were evaluated with pelvic ultrasound and if lower genitourinary tract cysts were present, the patients were further subjected to either trans-rectal ultrasound (TRUS), TRUS guided aspiration for presence of spermatozoa, TRUS guided seminal vesiculography or CT urography in order to reach the origin of the cyst and the complications of its presence. Results: 14 cases were detected with lower genitourinary tract cysts among our patients with an overall incidence 1.4\%; among them 3 patients with mid line prostatic cysts showed normal seminal analysis; 1 patient with prostatic cyst was infertile; 3 patients were detected with infravesical cysts after transurethral resection prostatectomy; 2 cases with small retention cysts were associated with benign prostatic hyperplasia; 1 case was detected with prostatic abscess; 1 patient was detected with unilateral ureterocele; 1 patient was detected with large pelvi abdominal unilateral seminal vesicle cyst; 1 patient was with unilateral ejaculatory duct cyst; 1 patient with small cystic dilation of prostatic urethra was associated with urethral stone.
\end{abstract}

Keywords: Cyst; Genitourinary; Male; Radiological

\section{Introduction}

Cysts of the prostate gland can be classified into 6 categories, including 1 ) isolated medial cysts; 2) cysts of the ejaculatory duct; 3) simple or multiple cysts of the parenchyma; 4) complicated infectious or hemorrhagic cysts; 5) cystic tumors; and 6) cysts secondary to parasitic disease [1]. Mid line prostatic cysts may contain sperms as ejaculatory duct and vas deference cysts or may be sperms free as utriculus and Mullerian duct cysts [2,3]. Seminal vesicles cysts are discovered incidentally, contain spermatozoa, may cause urinary symptoms and may be associated with unilateral renal agenesis or adult polycystic kidneys. Ejaculatory duct cysts could be congenital or acquired due to distal stenosis or obstruction which may lead to azoospermia and low or absent seminal fructose $[4,5]$. Prostatic cysts may be asymptomatic or may be associated with lower urinary tract irritative or obstructive symptoms and can lead to hematospermia or infertility [6-11]. Radiological evaluation of lower genitourinary tract cysts includes pelvic ultrasound, transrectal ul-

${ }^{*}$ Conflict of Interest: not present.

Sources of Funding: not present. trasound (TRUS), computed tomography, magnetic resonance imaging, TRUS guided aspiration of cyst contents and TRUS guided seminal vesiculography [4,12-15].

\section{Aim of the Work}

The present wok aims to assess how to reach the optimum diagnosis of the nature and the complications of lower genitourinary tract cyst in male patient using different radiological imaging modalities.

\section{Patients and Methods}

1000 male patients were complaining of lower urinary tract obstructive or irritative symptoms, their age range from 25 to 65 years and the mean age was 35 years, all were referred to pelvic ultrasound exam with Sonoace x8 ultrasound machine (Medison, Korea) using $3.5 \mathrm{mhz}$ convex ultrasound probe between October 2009 and May 2013 and if lower genitourinary tract cyst was present, the patients were further subjected to either trans-rectal ultrasound (TRUS), TRUS guided aspiration for presence of spermatozoa, TRUS guided seminal vesiculography or 
CT urography in order to reach the origin of the cyst and the complications of its presence. TRUS guided aspiration was done through introducing of $22 \mathrm{G}$ needle into the cyst guided with ultrasound to aspirate the contents and TRUS guided seminal vesiculography was done through introducing $22 \mathrm{G}$ needle into the seminal vesicles with injection of contrast media into each seminal vesicle. Patency of ejaculatory duct was diagnosed when filling of posterior urethra and urinary bladder with contrast media observed during injection [12-14].

\section{Results}

14 cases were detected with lower genitourinary tract cysts among our patients with an overall incidence 1.4\% as follows:

3 patients with mid line prostatic cysts showed normal seminal analysis, TRUS guided aspiration of cyst contents revealed no sperms suggesting either utriculus or Mullerian duct cysts (Figures 1 and 2).

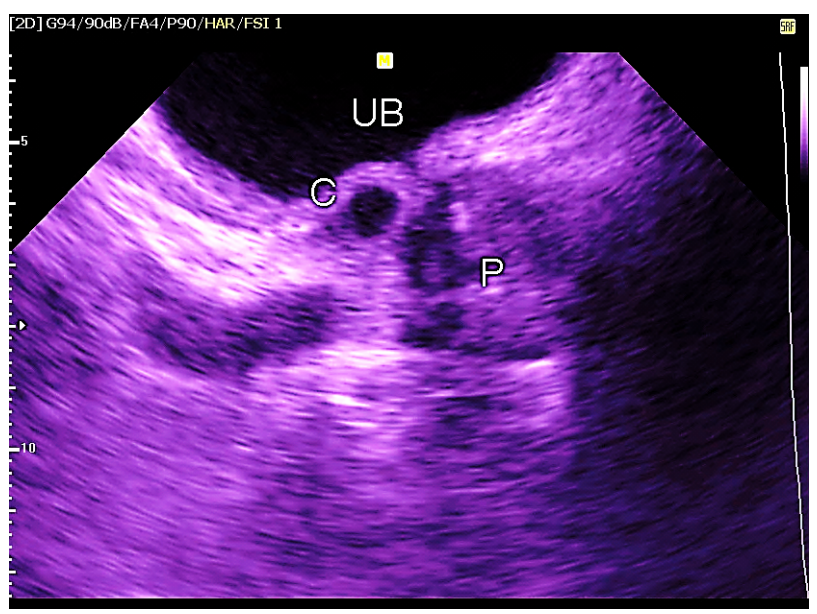

(a)

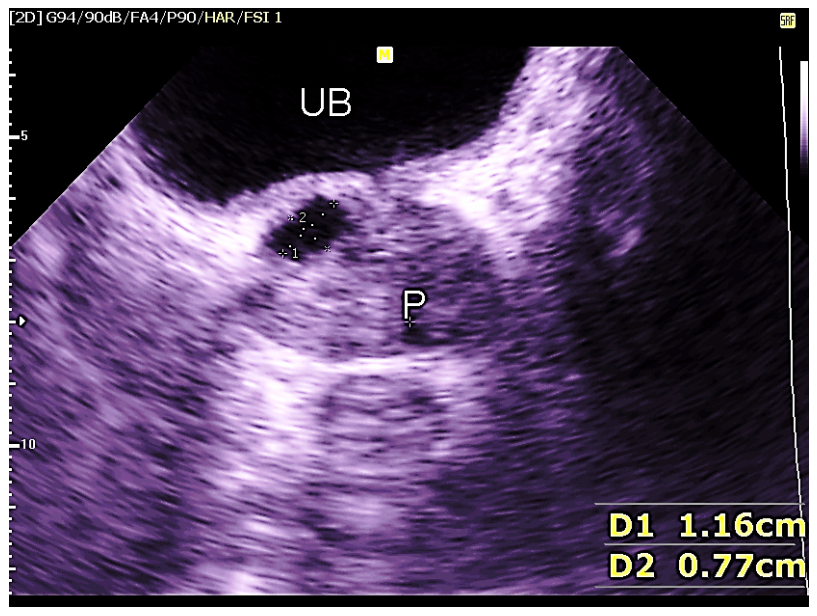

(b)

Figure 1. (a), (b): Small prostatic cyst seen at periphery of prostate adjacent to the urinary bladder neck.

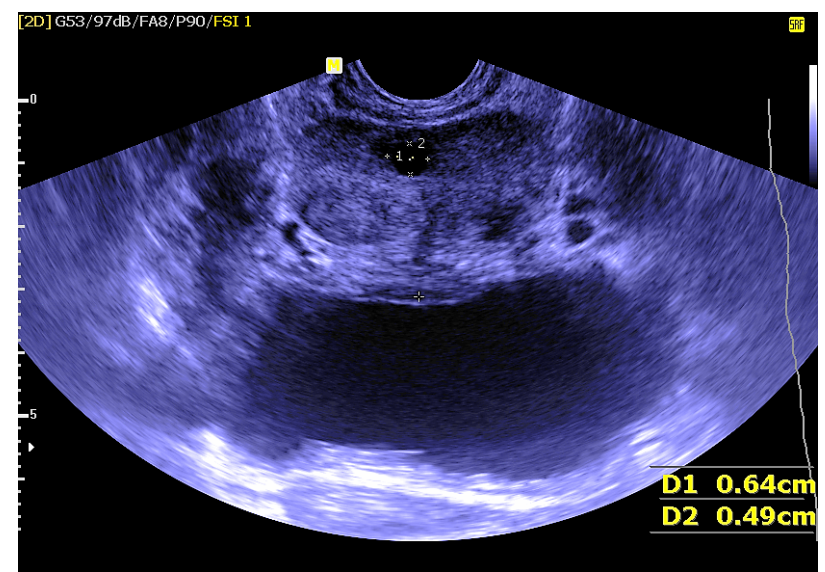

Figure 2. Small asymptomatic mid line prostatic cyst.

1 patient with prostatic cyst was infertile and showed azoospermia on seminal analysis with no filling of posterior urethra or urinary bladder with contrast during TRUS guided seminal vesiculography denoting bilateral ejaculatory ducts obstruction (Figures 3(a) and (b)).

3 patients were detected with infravesical cysts after transurethral resection prostatectomy.

2 cases with small retention cysts were associated with benign prostatic hyperplasia.

1 case with prostatic abscess showed severe lower urinary tract irritative symptoms, rectal pain and showed intraprostatic thick walls cavity with turbid contents that was markedly tender on probing (Figure 4).

1 patient was detected with unilateral ureterocele seen as distal localized fusiform dilation in the intramural course of ureter (Figure 5).

1 patient was detected with large pelvi abdominal cyst was complaining of severe lower urinary tract irritative symptoms with rectal heaviness and tenesmus, the cyst contents was turbid by ultrasound and further CT with contrast revealed that the cyst was originating from the right seminal vesicle and diagnosed as a rare case of large pelvi abdominal unilateral seminal vesicle cyst (Figures 6(a)-(d)).

1 patient with oligospermia showed unilateral ejaculatory duct cyst and was diagnosed with TRUS as small cystic swelling in the course of ejaculatory duct and TRUS guided aspiration revealed the presence of sperms.

1 case showed small localized cystic dilation of prostatic urethra associated with small stone at distal prostatic urethra.

\section{Discussion}

In spite of being very uncommon, lower genitourinary tract cysts in males may lead to male infertility, lower urinary tract obstructive and irritative symptoms and hematospermia [7-11]. With the use of TRUS, TRUS guided aspiration of the cyst, TRUS guided seminal vesiculo- 


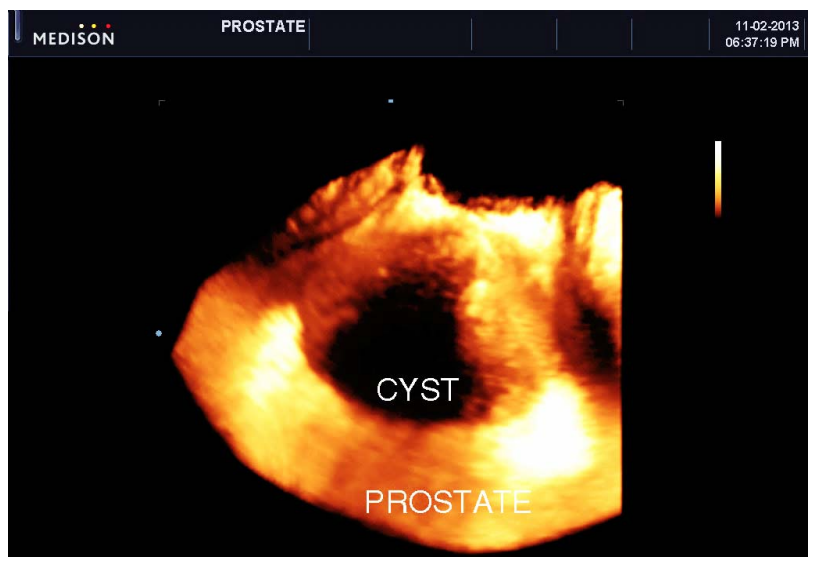

(a)

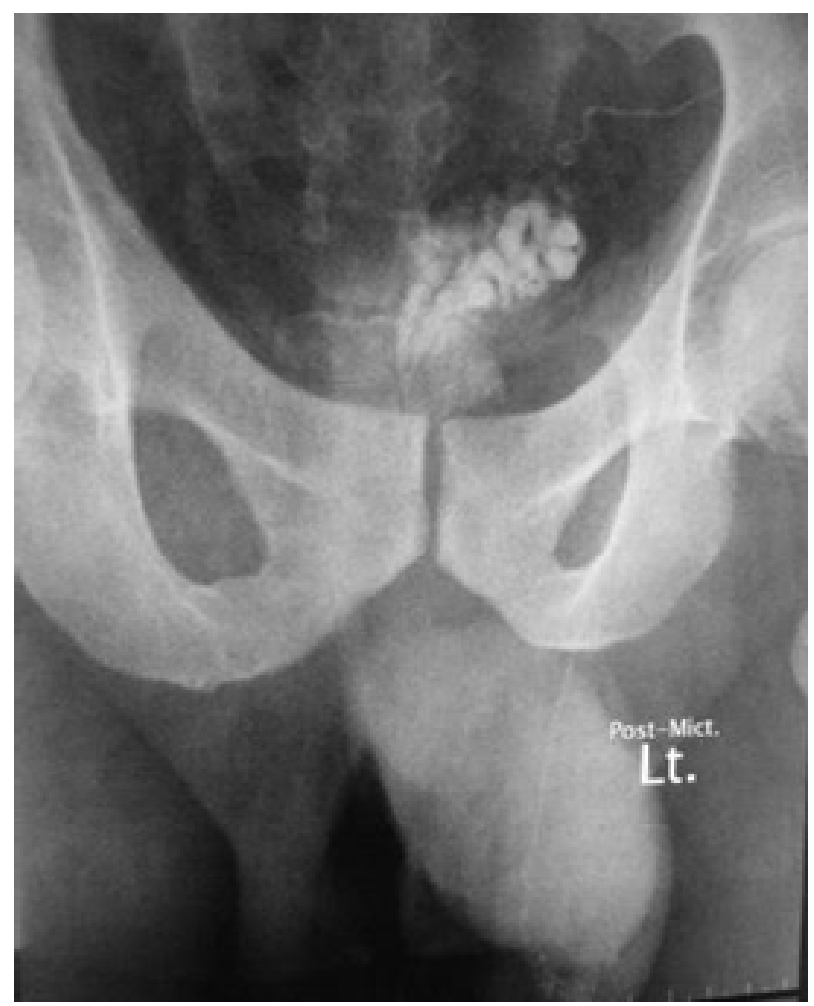

(b)

Figure 3. (a), (b): Prostatic cyst casting ejaculatory duct obstruction. (a) 3 dimensional ultrasound of large mid line prostatic cyst; (b) TRUS guided seminal vesiculography showing non filling of posterior urethra or urinary bladder denoting ejaculatory duct obstruction.

graphy and in selected cases CT urography in addition to the pelvic ultrasound, we can reach an accurate diagnosis to ensure an optimum way of management.

The differentiation between Mullerian duct cyst and utriculus cyst which are better referred as prostatic cyst is difficult as both occurs in midline of prostate and may cause infertility through compression or deviation of the ejaculatory ducts and both are sperm free; however, the differentiation is not important as both are treated with

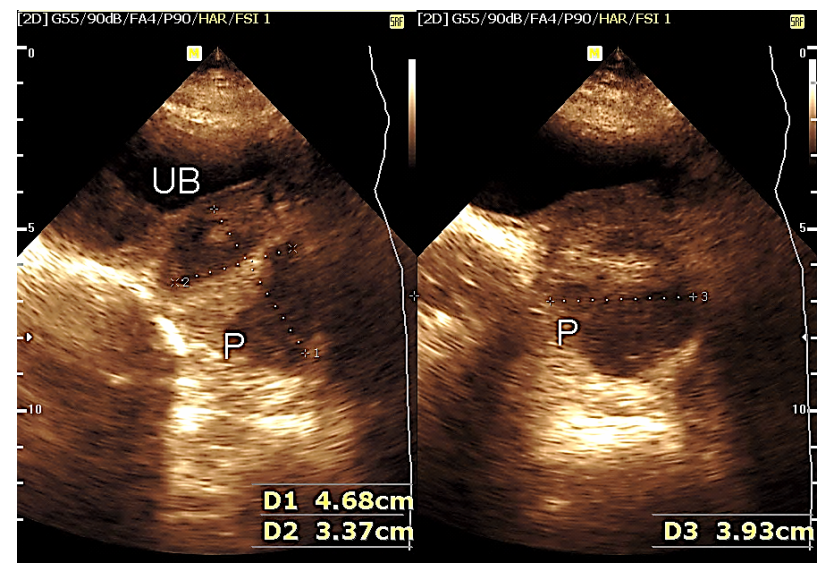

Figure 4. Pelvic ultrasound showing large prostatic abscess.

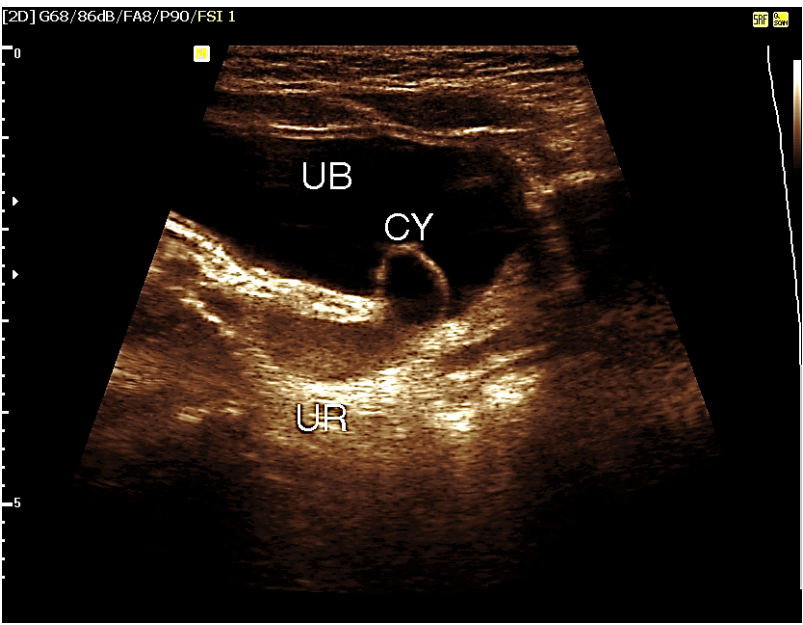

(a)

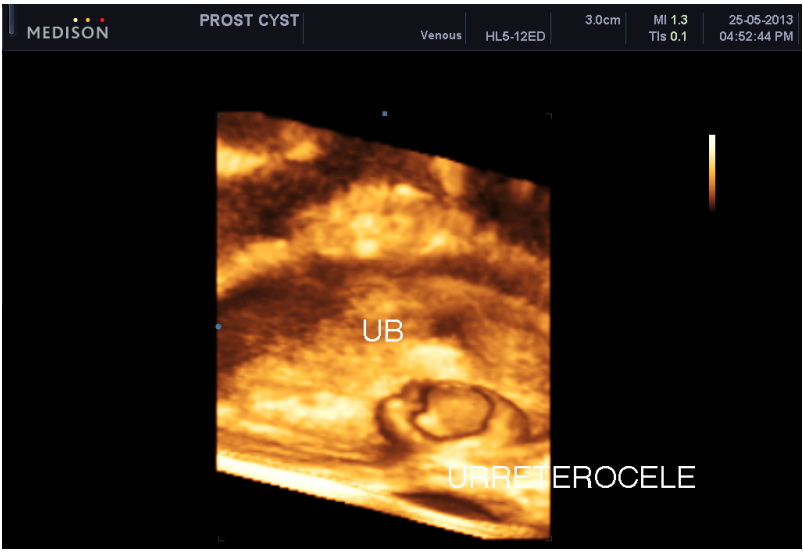

(b)

Figure 5. (a) Pelvic ultrasound showing right ureterocele; (b) 3 dimensional ultrasound of right ureterocele.

transurethral resection [11]. Many of them are asymptomatic but with the presence of azoospermia, TRUS guided seminal vesiculography was helpful to assess the presence of bilateral ejaculatory duct obstruction and the need for cyst resection. 


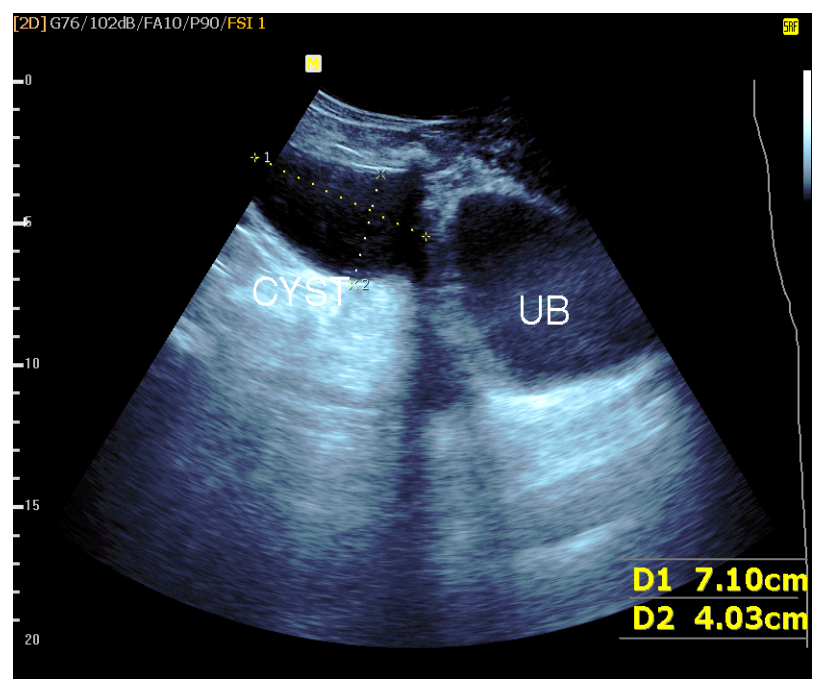

(a)

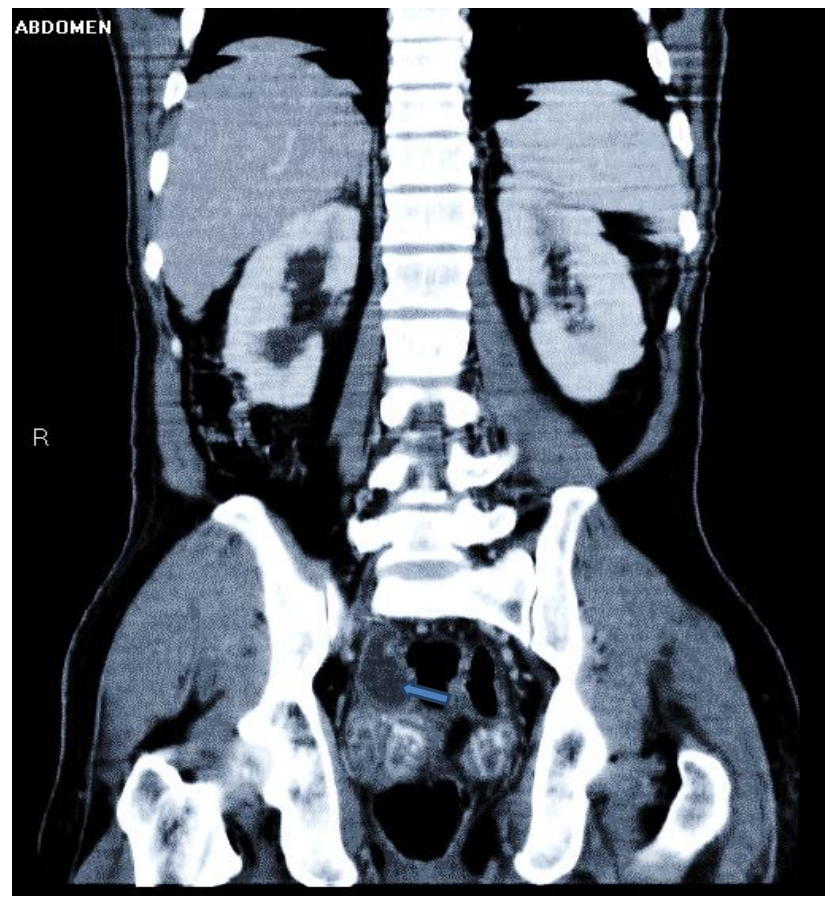

(c)

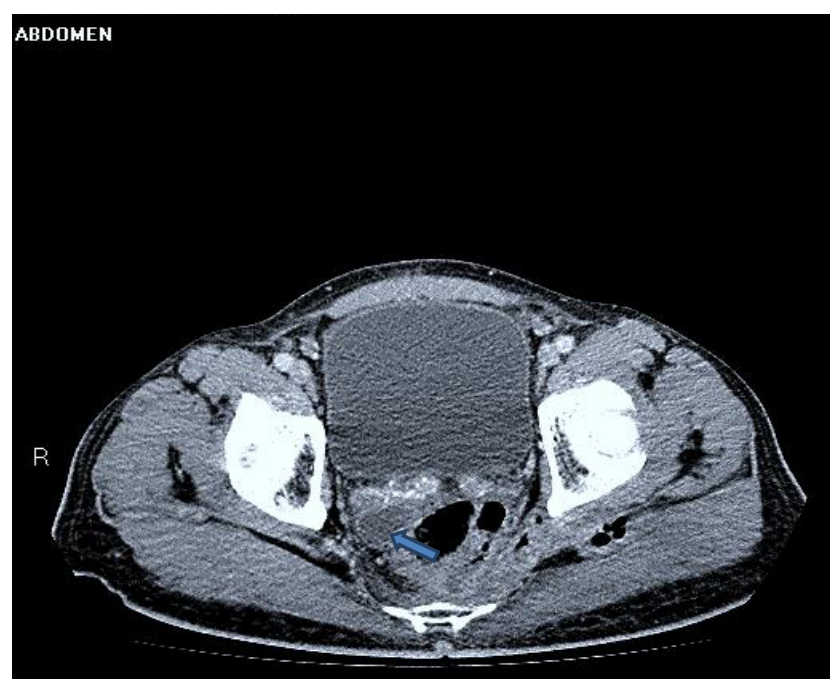

(b)

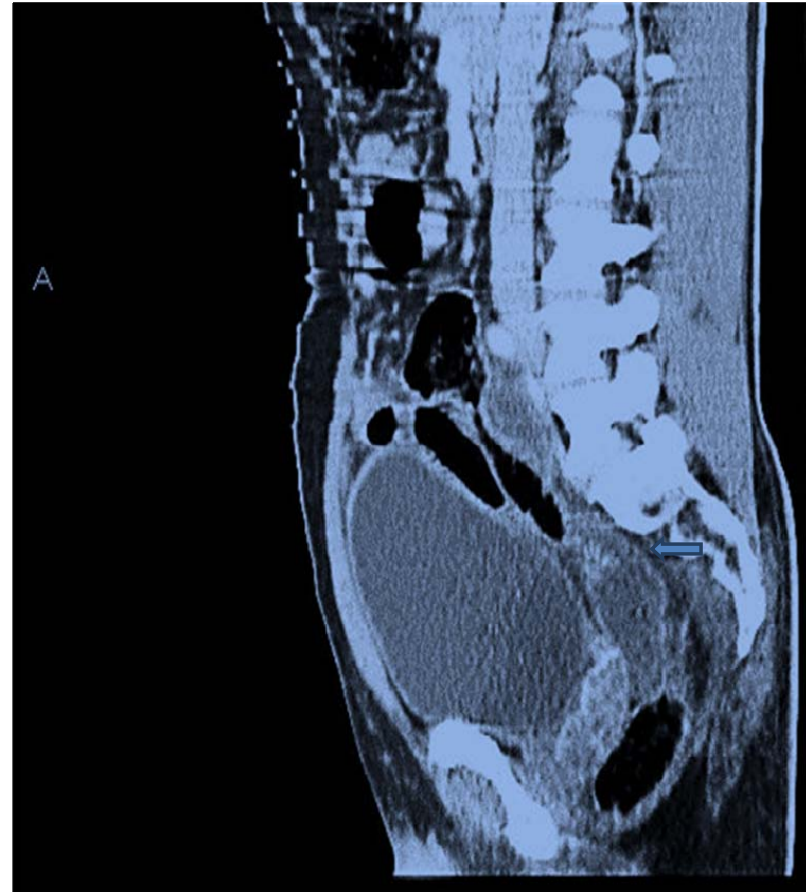

(d)

Figure 6. (a): B mode ultrasound showing pelvi-abdominal oblong shape cyst; (b)-(d): CT abdomen with contrast showing post billharzial calcified seminal vesicles with large pelvi-abdominal cyst (blue arrow) originating from the right seminal vesicle. (b): axial scan, (c): coronal scan and (d): sagittal scan.

Prostatic abscess was diagnosed by the clinical picture, the presence of intraprostatic thick walls turbid contents cavity with marginal hyperemia and by the presence of pus during TRUS guided aspiration.

Retention prostatic cysts are small anechoic clear content cysts seen in association with benign prostatic hyperplasia.

Ejaculatory ducts and vas deference cysts were diagnosed by their anatomical location in course of the ejaculatoy duct or the vas deference during TRUS and by the presence of spermatozoa in the aspirate using TRUS guided aspiration $[7,16]$.

Seminal vesicles cysts were diagnosed with pelvic ultrasound and TRUS by their origin from the seminal vesicles and in rare cases presented with plevi-abdominal swelling, CT with contrast proved useful in localizing their origin.

Ureteroceles are easily diagnosed by their characteristic location in intramural course of ureter.

In cases of Infra vesical cysts, after transurethral re- 
section prostatectomy, the diagnosis can be reached from the history and the characteristic funneling in the course of prostatic urethra.

\section{Conclusion}

Lower genitourinary tract cystic lesions are very uncommon in males and an accurate diagnosis of the nature and the complications of the cysts can be reached through good combination between various radiological imaging modalities, which is essential to reach the optimum way of management.

\section{REFERENCES}

[1] A. B. Galosi, R. Montironi, A. Fabiani, V. Lacetera, G. Gallé and G. Muzzonigro, "Cystic Lesions of the Prostate Gland: An Ultrasound Classification with Pathological Correlation,” Journal of Urology, Vol. 181, No. 2, 2009, pp. 647-657. http://dx.doi.org/10.1016/j.juro.2008.10.006

[2] J. P. Jarow, "Transrectal Ultrasonography of Infertile Men," Fertility and Sterility, Vol. 60, No. 6, 1993, pp. 1035-1039.

[3] S. Curran, O. Akin, A. M. Agildere, J. B. Zhang, H. Hricak and J. Rademaker, "Endorectal MRI of Prostatic and Periprostatic Cystic Lesions and Their Mimics,” Genitourinary Imaging, Vol. 188, No. 5, 2007, pp. 1873-1879.

[4] M. Arafa, A. Zytoon, H. Eid and A. Fathy, "A New Algorithm for Management of Ejaculatory Duct Obstruction Due to Prostatic Cyst in Infertile Males,” The Internet Journal of Radiology, Vol. 16, No. 1, 2013.

[5] G. Engin, M. Celtik, O. Sanli, O. Aytac, Z. Muradov and A. Kadioglu, "Comparison of Transrectal Ultrasonography and Transrectal Ultrasonography-Guided Seminal Vesicle Aspiration in the Diagnosis of the Ejaculatory Duct Obstruction," Fertility and Sterility, Vol. 92, No. 3, 2009, pp. 964-970. http://dx.doi.org/10.1016/j.fertnstert.2008.07.1749

[6] B. Dogan, A. E. Canda, Z. Akbulut, A. F. Atmaca, E. Duran and M. D. Balbay, "Prostatic Cyst Causing Severe Infravesical Obstruction in a Young Patient," Journal of Urology, Vol. 8, No. 4, 2011, pp. 330-332.
[7] J. S. Mayersak, “Urogenital Sinus-Ejaculatory Duct Cyst: A Case Report with Aproposed Clinical Classification and Review of the Literature,” Journal of Urology, Vol. 142, No. 5, 1989, pp. 1330-1332.

[8] E. C. Wessels, M. Ohori, J. E. Grantmyre, et al., "The Prevalence of Cystic Dilatation of the Ejaculatory Ducts Detected by Transrectal Ultrasound (TRUS) in a Self-Referred (Screening) Group of Men,” Journal of Urology, Vol. 147, No. 456A, 1992, Abstract 973.

[9] Z. Kirkali, O. Yigitbasi, B. Diren, et al., "Cysts of the Prostate, Seminal Vesicles and Diverticulum of the Ejaculatory Ducts,” European Urology, Vol. 20, No. 1, 1991 , pp. 77-80.

[10] J. S. Elder and J. L. Mostwin, "Cyst of the Ejaculatory Duct/Urogenital Sinus,” Journal of Urology, Vol. 132, No. 4, 1984, pp. 768-771.

[11] H. Van Poppel, R. Vereecken, P. De Geeter and H. Verduyn, "Hemospermia Owing to Utricular Cyst: Embryological Summary and Surgical Review,” Journal of Urology, Vol. 129, No. 3, 1983, pp. 608-609.

[12] D. Katz, M. Mieza and H. M. Nagler, "Ultrasound Guided Transrectal Seminal Vesiculography: A New Approach to the Diagnosis of Male Reproductive Tract Abnormalities," Journal of Urology, Vol. 151, No. 310A, 1994, Abstract 330

[13] J. P. Jarow, "Seminal Vesicle Aspiration in the Management of Patients with Ejaculatory Duct Obstruction," Journal of Urology, Vol. 152, No. 3, 1994, pp. 899-901.

[14] I. Orhan, R. Onur, S. Cayan, et al., "Seminal Vesicle Sperm Aspiration in the Diagnosis of Ejaculatory Duct Obstruction,” BJU International, Vol. 84, No. 9, 1999, pp. 1050-1053.

http://dx.doi.org/10.1046/j.1464-410x.1999.00379.x

[15] P. J. Littrup, F. Lee, R. D. McLeary, et al., “Transrectal US of the Seminal Vesicles and Ejaculatory Ducts: Clinical Correlation,” Radiology, Vol. 168, No. 3, 1988, pp. 625-628.

[16] H. Takatera, H. Sugao and T. Sakurai, "Ejaculatory Duct Cyst: The Case for Effective Use of Transrectal Longitudinal Ultrasonography,” Journal of Urology, Vol. 137, No. 6, 137, 1987, pp. 1241-1242. 